\title{
Correction to: Search and rescue with autonomous flying robots through behavior-based cooperative intelligence
}

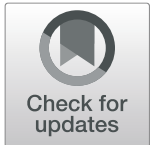

Ross D. Arnold ${ }^{1 *}$, Hiroyuki Yamaguchi ${ }^{2}$ and Toshiyuki Tanaka ${ }^{2}$

\section{Correction to: J Int Humanitarian Action https://doi.org/10.1186/s41018-018-0045-4}

Following publication of the original article (Arnold et al. 2018), the authors reported errors. First error can be found in Funding section and second error in Endnote 5.

The updated Funding section is provided below.

\footnotetext{
Funding

Funding was provided by the Japan Acquisition, Technology and Logistics

Agency. The authors are employees of these agencies.
}

The correct text in Endnote 5 should read:

${ }^{5}$ The DroneLab simulation software, as well as the UAV controlling software, may be available upon request to the paper's corresponding author. At the time of this writing, the software is not public domain.

\section{Author details}

${ }^{1}$ United States Army Armament, Research, Development, and Engineering Center (US Army ARDEC), United States Department of Defense, Picatinny, NJ, USA. ${ }^{2}$ Acquisition, Technology and Logistics Agency (ATLA), Japan Ministry of Defense, Tokyo, Japan.

Published online: 01 June 2019

\section{Reference}

Arnold RD, Yamaguchi H, Tanaka T (2018) Search and rescue with autonomous flying robots through behavior-based cooperative intelligence. J Int Humanitarian Action 3:18 https://doi.org/10.1186/s41018-018-0045-4

\footnotetext{
* Correspondence: ross.arnold1@gmail.com; ross.d.arnold4.civ@mail.mil The original article can be found online at https://doi.org/10.1186/s41018018-0045-4

${ }^{1}$ United States Army Armament, Research, Development, and Engineering Center (US Army ARDEC), United States Department of Defense, Picatinny, NJ, USA

Full list of author information is available at the end of the article
} 